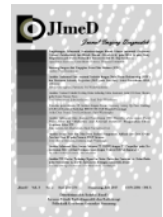

Jurnal Imejing Diagnostik (JImeD) 7 (2021) 111-113

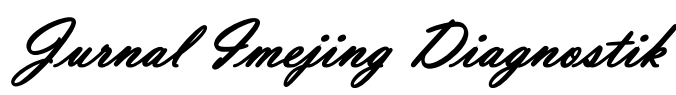

e-ISSN 2621-7457, p-ISSN 2356-301X

\title{
Uji Kesesuaian Berkas Cahaya Kolimasi Pada Pesawat Sinar-X Di Politeknik Al-Islam Bandung
}

\author{
Oktarina Damayanti ${ }^{1}$, Indra Gunawan ${ }^{2}$ \\ ${ }^{1,2)}$ Politeknik Al Islam Bandung, Indonesia \\ Corresponding Author : Oktarina Damayanti \\ email: oktarina.st@gmail.com
}

Received: July 29 ${ }^{\text {th }}$, 2021; Revised: July $31^{\text {st }}$, 2021; Accepted: July $31^{\text {st }}, 2021$

\begin{abstract}
Background: Suitability tests for light collimation are tests to ensure that $\mathrm{x}$-ray aircraft meet radiation safety requirements and provide precise and accurate diagnostic or diagnostic information. Suitability test for light collimation is carried out on X-ray aircraft at Al-Islam Bandung Politeknik.

Methods: The research method used in quantitative experimental methods. The suitability test was carried out with a collimator test tool and beam alignment test tool placed on the tape then performed an experiment using an exposure factor of $75 \mathrm{Kv}, 200 \mathrm{~mA}$ and $8 \mathrm{mAs}$ with FFD $100 \mathrm{~cm}$.

Results: Based on the tests that have been carried out, it is known that there is a discrepancy in the width of the collimation beam. The large discrepancy between the light field area and the radiation field area, that is, the edge $X_{1} 0.3 \mathrm{~cm}$, the edge $X_{2} 0.5 \mathrm{~cm}$, the edge $Y_{1} 0.5 \mathrm{~cm}$, the edge $Y_{2} 0.1 \mathrm{~cm}$. So the value of $\Delta X$ is $0.8 \% \mathrm{FFD}$, the value of $\Delta \mathrm{Y}$ is $0.6 \% \mathrm{FFD}$, and the value of $\Delta \mathrm{X}+\Delta \mathrm{Y}$ is $1.4 \% \mathrm{FFD}$. While the deviation of the central point is less or right than $3^{\circ}$. These results indicate that the discrepancy in the width of the light beam collimation and center point deviations is still within the tolerance limits.

Conclusions: There is a discrepancy between the X-ray light field and the collimated light field, but it is still within the limit of the test value to the passing value of the predefined test.
\end{abstract}

Keyword: suitability test, collimation, collimator test tool and beam alignment test tool.

\section{Pendahuluan}

Pada pemeriksaan pasien agar tidak terjadinya penyimpangan hasil gambaran maka perlu dilakukan uji kesesuaian pada alat. Uji kesesuaian adalah uji untuk memastikan bahwa pesawat sinar$\mathrm{x}$ memenuhi persyaratan keselamatan radiasi dan memberikan informasi diagnosis atau pelaksanaan radiologi yang tepat serta akurat. Uji kesesuaian juga merupakan suatu program jaminan mutu pengujian kesesuaian luas collimator beam dengan luas berkas tabung sinar-x. Pengujian ini bertujuan agar tidak terjadinya pergeseran sudut atau jarak pada tabung sinar-x sehingga lebih tepat dan akurat untuk menentukan lokasi atau gangguan dalam tubuh manusia. Dengan demikian tujuan dari jaminan mutu adalah mengurangi paparan radiasi, peningkatan citra diagnostik dan penekanan biaya. Untuk memastikan bahwa pesawat sinar-X memenuhi persyaratan keselamatan radiasi dan memberikan informasi diagnosis maka diperlukan uji fungsi atau uji kesesuaian. Uji kesesuaian merupakan dasar dari suatu program metode kendali mutu yang mengacu pada prinsip ALARA (As low As Reasonably Achievable). Pengujian kolimasi satu bulan sekali atau setelah perbaikan atau perawatan rumah tabung dan kolimator. Frekuensi pengujian dapat diperbanyak tergantung dengan besarnya beban penggunaan pesawat. (Kemenkes, 2009).

Menurut hasil observasi penulis ingin menguji kesesuaian berkas cahaya kolimasi pesawat sinar- $\mathrm{x}$ di Laboratorium Politeknik Al-Islam Bandung.

\section{Metode}

Jenis penelitian yang digunakan dalam penelitian ini adalah metode eksperimental kuantitatif. Uji kesesuaian dilakukan dengan alat collimator test tool dan beam alignment test tool yang diletakan di atas kaset kemudian dilakukan eksposi dengan menggunakan faktor eksposi sebesar $75 \mathrm{Kv}, 200$ mA dan 8 mAs dengan FFD 100 $\mathrm{cm}$. 


\section{Hasil dan Pembahasan}

Peralatan yang digunakan :

1. Pesawat Sinar-X merk Toshiba

2. Kaset dan Film ukuran $24 \times 30 \mathrm{~cm}$

3. collimator test tool

4. beam alignment test tool

5. Alat tulis : Pulpen, buku, mistar

6. Form hasil pengujian

7. Pedoman observasi

Langkah-langkah penelitian adalah :

1. Mempersiapkan semua alat yang dibutuhkan

2. Menyalakan pesawat sinar-X

3. Pengaturan faktor eksposi, Kv 75, mA 200, mAs 8,0

4. FFD $100 \mathrm{~cm}$

5. Collimator test tool dan beam alignment test tool yang diletakan di atas kaset

6. Melakukan eksposi

7. film diproses menggunakan processing film manual.

8. Analisa hasil radiograph

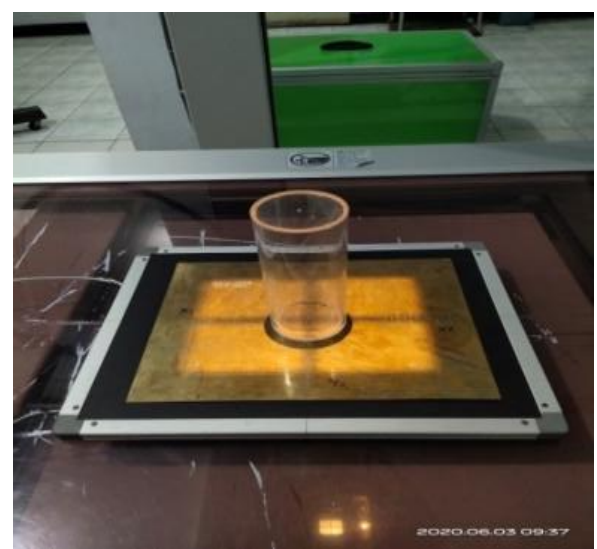

Gambar 1. Posisi Collimator Test Tool dan Beam Alignment Test Tool

Hasil yang didapat dari penelitian yang dilakukan penulis dapat dilihat dari gambar dibawah ini

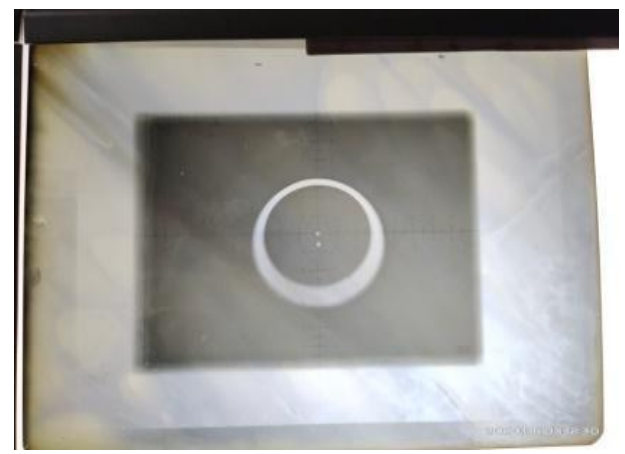

Gambar 2. Hasil Pengujian Berkas Cahaya Kolimasi

\section{Hasil Pengukuran Luas Lapangan Kolimasi}

Berdasarkan pengukuran dari pengujian terhadap berkas cahaya kolimasi pada pesawat rontgen merk Toshiba di Politeknik Al-Islam Bandung yang telah penulis lakukan, ditemukan adanya perbedaan luas lapangan cahaya kolimasi dengan luas lapangan hasil citra sinar-X. Hasil pengukurannya adalah sebagai berikut.

X1 = Lapangan Cahaya - Lapangan Sinar-X

$$
=9,2-9,5=0,3 \mathrm{~cm}
$$

X2 = Lapangan Cahaya - Lapangan Sinar-X

$$
=9-8,5=0,5 \mathrm{~cm}
$$

$\mathrm{Y} 1=$ Lapangan Cahaya - Lapangan Sinar-X $=7-6,5=0,5 \mathrm{~cm}$

Y2 = Lapangan Cahaya - Lapangan Sinar-X $=7,1-7,2=0,1 \mathrm{~cm}$

Total penyimpangan lapangan cahaya dengan lapangan sinar-X pada sumbu $\mathrm{X}$ dan sumbu $\mathrm{Y}$ adalah sebagai berikut :

$$
\begin{aligned}
\Delta \mathrm{X} & =\mathrm{X} 1+\mathrm{X} 2 \\
& =0,3+0,5=0,8 \% \\
\Delta \mathrm{Y} & =\mathrm{Y} 1+\mathrm{Y} 2 \\
& =0,5+0,1=0,6 \%
\end{aligned}
$$

\begin{tabular}{|c|c|c|c|c|}
\hline $\begin{array}{l}\text { Titik } \\
\text { ukur }\end{array}$ & $\begin{array}{l}\text { Tepi lap. } \\
\text { Cahaya } \\
(\mathrm{cm})\end{array}$ & $\begin{array}{l}\text { Tepi lap. } \\
\text { Cahaya } \\
(\mathrm{cm})\end{array}$ & $\begin{array}{l}|\Delta 1|+|\Delta 2| \\
(\% \text { FFD) }\end{array}$ & $\begin{array}{l}|\Delta \mathrm{X}| \\
+ \\
|\Delta \mathrm{Y}| \\
(\% \\
\text { FFD) }\end{array}$ \\
\hline $\mathrm{X} 1$ & 9,2 & 9,5 & 0,8 & 1,4 \\
\hline $\mathrm{X} 2$ & 9 & 8,5 & & \\
\hline Y1 & 7 & 6,5 & 0,6 & \\
\hline $\mathrm{Y} 2$ & 7,1 & 7,2 & & \\
\hline \multicolumn{3}{|c|}{ Toleransi } & $\leq 2 \div \mathrm{FFD}$ & $\begin{array}{l}\leq 3 \% \\
\text { FFD }\end{array}$ \\
\hline
\end{tabular}

Total penyimpangan lapangan cahaya dengan lapangan sinar- $X$ adalah sebagai berikut :

$$
|\Delta \mathrm{X}|+|\Delta \mathrm{Y}|=0,8+0,6=1,4 \% \mathrm{FFD}
$$

Tabel 1. Hasil Nilai Perhitungan

Batas toleransi untuk nilai kongruensi luas lapangan kolimasi yang telah ditetapkan oleh National Council on Radiation Protection (NRCP),yaitu :
a. $(\mathrm{X} 1+\mathrm{X} 2) \leq 2 \% \mathrm{FFD}$
b. $(\mathrm{Y} 1+\mathrm{Y} 2) \leq 3 \% \mathrm{FFD}$
c. $|\Delta X|+|\Delta Y| \leq 3 \% F F D$

Setelah dilakukan pengujian dan pengukuran terhadap berkas cahaya kolimasi pada pesawat rontgen merk Toshiba di Politeknik Al-Islam Bandung, diketahui bahwa terjadi ketidaksesuaian luas lapangan kolimasi dengan luas lapangan sinar$\mathrm{X}$. Tetapi, nilai ketidaksesuaian luas lapangan berkas cahaya kolimasi masih dalam batas toleransi yang disepakati. 


\section{Hasil Pengukuran Titik Pusat Kolimasi}

Hasil Pengukuran Titik Pusat kolimasi pada pesawat rontgen yang ada di laboratorium Politeknik Al-Islam Bandung ditemukan adanya penyimpangan titik pusat. Hal tersebut dilihat dari gambar bola baja yang terdapat pada bagian atas dan bawah beam alignment test tool tidak superposisi. Penyimpangan titik pusat menunjukan tepat atau kurang dari $3^{0}$ yang berarti bahwa penyimpangan titik pusat masih dalam batas toleransi yang disepakati.

\section{Simpulan}

Hasil uji berkas cahaya kolimasi pada pesawat rontgen di Politeknik Al-Islam Bandung, terjadi ketidaksesuaian luas lapangan cahaya sinar-X dengan luas lapangan cahaya kolimasi dimana luas lapangan cahaya sinar-X keluar lebih kecil daripada luas lapangan cahaya kolimasi. Sesuai dengan yang ditetapkan oleh National Council on Radiation Protection (NRCP) nilai ketidaksesuaian luas lapangan berkas cahaya kolimasi masih dalam batas toleransi yang disepakati.

\section{Daftar Pustaka}

Akhadi, M. 2001. Dasar-Dasar Proteksi Radiasi: PT. Rineka Cipta.

Aningsih, Endang Rahayu Sedy. 2009. Uji Kesamaan Berkas Cahaya Kolimator. Jakarta: Kemenkes RI.

Badan Pengawas Tenaga Nuklir. 2018. Peraturan Badan Pengawas Tenaga Nuklir Tentang Uji Kesesuaian Pesawat Sinar-X Radiologi Diagnostik dan Intervensional. Jakarta: BAPETEN.

Bushong, Stewart C. 2013. Radiologic Science for Technologists. (10th ed) St. Louis: Mosby.

Ferderbar, Michelle. 2015. Field Congruency and Beam Perpendicularity. Dari http://qcinradiography.weebly.com/light-fieldcongruency-test 